\title{
Every Picture Tells a Story: combining Interpretative Phenomenological Analysis with Visual Research.
}

\section{Abstract}

This article will present a methodological critique of the research process which combines participant generated imagery with Interpretative Phenomenological Analysis (IPA). This critique is based upon a research study which aimed to understand how social work practitioners experience their transition into firstline management. This study was particularly concerned with understanding feelings associated with role transitions within social work, as it is an underresearched area of practice. The data (verbal and visual) collected from the study was analysed using an adaptation of the IPA six-stage process. A rationale is provided to illustrate the synergy between the underlying principles of IPA as a research methodology and the social work profession, together with the need to adopt a nuanced and innovative approach through the utilisation of visual research methodology[. Limitations and possibilities associated with combining these two research approaches will be illustrated through a series of examples from the study. It will conclude that the synergy of research approaches contribute to a deeper understanding of lived experience.

Key words: visual research method, IPA, transitions

Ethics: Ethical approval was sought and gained from the University of Northampton Research Committee. Pseudonyms are used throughout this paper.

\section{Introduction}

The aim of this paper is to provide a methodological critique of the research process which combines participant generated imagery with Interpretative Phenomenological Analysis (IPA). This critique is based upon a doctoral research study drawing upon a research study which explored the transition from social worker to first line manager from the perspective of newly appointed managers, with an emphasis on individual perspectives. This study was particularly concerned with understanding feelings associated with occupational transitions within social work, as it is an under-researched area of practice. As one of the participants reflected, this is a question which is overlooked because: 
No-one ever asks (Michelle).

Concerned with facilitating the voice of new first line social work managers within Children's Services, the study focused upon their experience of role transition. The articulation of voice was conceptually connected to issues of participation and empowerment (Thomson, 2009). It also favoured excluded or silent voices over dominant ones (Warren, 2007). This is particularly relevant within the context of the study as narratives about the profession are often dominated and conveyed by politicians and the media rather than practitioners or their managers. Therefore, in order to capture the varied, diverse and emotive experiences of new managers, an innovative research approach is developed. This approach combines IPA together with visual research method to illustrate the individual nature of participants' experiences. The combination of IPA and visual methods was used as a means of facilitating the differing accounts of transition into first line management in order to recognise the fragmented and individual nature of this experience.

\section{Social Work and IPA - a good match?}

IPA is a methodological approach underpinned by three main theoretical influences: phenomenology, hermeneutics and idiography. Phenomenology, the philosophical approach to the study of experience, resonates with the International definition of social work which outlines the profession's main intentions associated with human experience (International Federation of Social Work , 2014). Hermeneutics, the branch of knowledge that deals with interpretation. Idiography is concerned with the particular, which, like social work emphasises the uniqueness of experience (British Association of Social Work, 2012). This emphasis on the particular means that IPA studies often involve a small number of participants. Furthermore, the study focused upon new social work managers' experiences, thus from a methodological perspective, IPA is consistent with this epistemological position. Similarly, with strong ideals connected with addressing power imbalances, social workers strive to ensure that rapport is built with service users effectively and meaningfully. This rapport building is typically formed within a face-to-face interview with service users. Likewise as a data collection method it is agreed that IPA is most appropriate in 
that it invites participants to a research interview to share a detailed first-person account of their experience (Smith, 2015). Therefore, similarities can be found in the shared methods adopted by both the social worker and IPA researcher to gain narratives connected to the individual's world and point of view.

Hefferon and Gil-Roderiguez (2011) note that, due to IPA's focus on subjective lived experience and its roots in health psychology, IPA remains appealing within health, psychology and counselling research and less known and used in other disciplines (Brocki \& Wearden, 2006; Pringle et al., 2011; Smith et al., 2009). This is also true within social work research, where IPA is comparatively underused and rare (Loo, 2012). IPA seeks to find meaning in individual experience, which is similar to the objectives of the social work task, therefore IPA's general absence within social work research and what Houston \& MullenJensen (2012, p. 3) refer to as a "dearth of application" is somewhat surprising.

\section{Visual Methods}

Visuals are part of everyday life, featuring in our world in the form of images and artefacts that communicate and depict aspects of our social lives and cultures (Rose , 2012; Silver, 2013). There has been a significant growth in the past thirty years of visual research in the social sciences which Reavey (2011) attributes to the growing importance placed on culture and exposure to imagery due to mass media and, arguably, social media. The use of visual methods can also be seen growing in psychology research (Reavey, 2011; Silver, 2013), social work (Huss, 2012), health (Guillemin, 2004) more generally (Emmison, Smith, \& Mayall, 2012).

There is a growing body of evidence which suggests that visual research methodologies are being applied to qualitative research. These include participant generated imagery which this study adopts. Visual imagery is a wellestablished research method within the social sciences (Pauwels, 2015). This is a method where visual mediums (images or objects) can be generated by the researcher or participant (which they have found or created). In this study the participants were invited to generate their own visual representation. The use of 
visual imagery is regarded as a useful method for exploring change and life stages (Del Busso, 2011) making it appropriate for this study where the intention is to understand the role transition.

The study was prompted by prior conversations with new managers which revealed anecdotal evidence suggesting their experience of transition is largely ignored. These same conversations highlight that new managers often describe their role transition in the form of visual metaphors to illustrate their feelings of being isolated and overwhelmed. Such metaphors included: 'sink or swim' or 'being thrown in the deep end'. Subsequently, the research design is based on the belief that relying upon words alone can obscure the complexities and feelings associated with transition and that images could reveal more than words (Mannay, 2016; Ray \& Smith, 2012). Furthermore, social workers are accomplished in seeking and using creative forms of communication and expressive skills when engaging with service users (Burgess \& Laurance, 2007). This, together with the anecdotal evidence of using visual metaphors, shaped the design of this study and an assumption was made that using visual imagery was a familiar way for participants to express and depict their experiences of transition.

\section{The study: methods, participants and design}

Congruent with the conventions of IPA research, nine participants were recruited to this study with the aim of representing a perspective rather than a population (Smith et al. 2009). In this context the 'homogeneity' relates to individual social workers who became managers within Children's Services within the six months prior to the research interview being conducted. Participants were requested to bring to the research interview an image or object that represented their transition from social worker to manager. In the participant documentation, it was explained that the visual representation could be an image and/or object that the participant had taken or made themselves, for example a drawing or photograph. Likewise, the image/object could be one that the participant owned, or had found on the internet or in a magazine. Semi-structured one-to-one interviews, typically lasting between one and two hours were conducted, with 
visual representations as a means of eliciting data and serving as a catalyst to the discussion. An interview schedule of open-ended questions served to guide rather than lead the interview.

\section{Analysis: IPA a six step (adapted) process}

Whilst there are similarities in the ways that IPA has been applied by researchers, the relative newness of IPA as a research approach lends itself to being open to adaption and to evolve creatively. Central to IPA is the six-step approach to analysis which was adapted for the purposes of the study by the researcher and author of this paper. The adapted model (see figure 1) relates primarily to the integral positioning of the visual materials to the research design. Others have also creatively applied the IPA six stage analytical process to take into account the centrality of both visual material and related metaphors (Lee \& Skewes McFerran, 2015; Kirkham et al., 2015).

The adapted IPA process applied to this study is summarised in figure 1 . The initial step was the immersion of the researcher in the reading and re-reading of the original data and checking the transcripts for accuracy against tape recordings. At this stage transcripts were also listened to whilst examining the participants' images and objects. This allowed for the use of two human senses, sight and hearing, to further understand participants' experiences more closely and to ensure that both their words and visual representations remain central to the analytical process.

The second step which Smith et al. describe as the "most detailed and time consuming" involves making initial notes which explore semantic content and language (2009, p. 83). At this stage, the IPA process was again adapted to take into account sections of the transcript which related to participants' visual representations of transition.

During the third step emergent themes were noted and at the fourth step a search for connections across emergent themes were collated within a table. At 
step 5 was process is repeated by moving onto the next case. The final step, 6, involved looking for patterns across all nine cases. It is important to stress that as a means of paying particular attention to the uniqueness of experience, IPA is concerned with convergence and divergence and not just in shared themes (Loo, 2012).

- Immersion in the reading and re-reading of the original data (alongside
visual data), checking the transcripts for accuracy against audio tape
recordings, ensuring that the participant remains central to the analytical
process.

IPA promotes the use of available theoretical knowledge to help interpret the findings (Cronin-Davis \& Mayers, 2009; Smith, 2015). This resonates with the practice of social work where theoretical knowledge can be drawn upon to illuminate understandings of people and their circumstance (Trevithick, 2005). Therefore, IPA can be seen as serving a dual purpose: to explore the participants' perceptions of their world, whilst integrating the researcher's interpretation of that world (Pietkiewicz \& Smith, 2014). This process of 
interpretation is referred to as the hermeneutic circle which lies within the analytical stage of IPA. This is when the researcher is making sense, or in other words interpreting how the participants make sense of their own experience. Nevertheless, whilst IPA promotes the use of theoretical assumptions, the act of interpretation is imbued with notions of ethics and the portrayal of 'truth' whilst trying to remain close to the data. Therefore interpretation is seen as a means of contributing to the findings rather than superimposing the researcher's own views over those of the participants. Subsequently IPA advocates that participant's words are used verbatim to ensure that their voice remains integral to the (re)telling of their stories (Smith, Flowers, \& Larkin, 2009).

To this end, all the interviews were audio recorded and photographs were taken of images/objects produced with participants' permission. The interviews were transcribed verbatim allowing the words of the participants to become alive and lead the inductive and iterative process. Smith et al. recommend a "semantic record" of the research interview, in other words a transcript that reflects all of the spoken words (2009, p. 78). Likewise, the transcripts in this study included what was observed as well as what was heard in terms of significant pauses, hesitations, non-verbal communication (e.g. nodding, facial expressions) and other enunciations such as laughter.

\section{Limitations and possibilities of combining research methods}

The combining of IPA and visual research methods is relatively rare. However more recently published studies, where a fusion of these methods has been applied, suggests a growing interest in qualitative researchers seeking creative ways in gaining deeper understandings of complex human experience ( (Boden, Larkin, \& Malvika , 2019; Kirkham et al., 2015; Lachal, et al., 2012; Palaloukas et al., 2017; Shinebourne \& Smith, 2011). A number of limitations and possibilities can arise when engaging in new research approaches which this study encounters.

\section{Limitations}


The use of visual methods can be challenging for a number of reasons. One of these relates to issues associated with the multiple meaning attributed to images and the analytical approaches adopted (Prosser, 2011; Reavey, 2011). Whilst striving to keep the research design and guidance given to participants prior to the interview flexible and open, there still is an element of guidance provided through the participant information documentation. As Mannay (2013, p. 139) argues, even the slightest direction can influence the data generated as this "implies some form of assignment at the point of data production". This was particularly noticeable in Maureen's case, she brought three images to the interview (figure 2, 3 and 4).

(Figure2)

(Figure3)

(Figure4)

She recounts how initially she had a dilemma which she described as a mismatch between the visual representations that she imagined in contrast to the one that she assumed she was expected to produce. Maureen ponders on her dilemma and shares candid questions that she poses to herself to help her in choosing the 'right' image (figures 2-4):

Who was I choosing the picture for? For your research or for me? So I was trying to be honest . . .

Maureen's dilemma in relation to what and how she visually represents her transition appears bound up with notions of the intended audience (in this case the researcher) and congruence. This dilemma and mismatch between image maker and image viewer is debated in the literature (Chalfen \& Lutrell, 2010; Rose, 2012). Also connected to this is the method of semiology (sometimes referred to as semiotics) to visual methodologies. Semiology directly addresses the question of how images create meanings and how semiologists "chose their images on the basis of how conceptually interesting they are; they select images that will make their point well" (Rose , 2012, p. 109). Maureen's dilemma illustrates this point. Although she is invited to bring an image and/or object she brings three images to the interview. Despite all three images being meaningful to her story of transition, Maureen is critical of them in terms of their aesthetic value. For example she describes her first image as . . . not a very nice picture. . . the second as slightly cartoonish and finally the image of the Great Wall of China as 
I was just looking for a strong wall because I think that all the bricks are important in a wall.

In the absence of an explanation, and adopting a hermeneutic stance, the three images could be attributed to either Maureen's indecisiveness or a reflection of an inner strength through wider and interconnected systems such as chains, links and walls. Theoretically, the understanding of images as seen through the intentions of the creator is known as auteur theory (Rose , 2012), later developed by Mannay $(2013 ; 2016)$ who suggest that often the interpretation of the viewer and the intentions of the image creator can be significantly different. This further accentuates the need for an accompanying narrative to visual materials, which is particularly relevant to this study which is concerned with giving voice to participants.

As illustrated, images in research interviews can encourage participants to talk about the researchers' potential interpretation instead of their own (Prosser, 2011). A further example emerges with Sandra, who seeks reassurance that the narrative accompanying her two objects (a book and bracelet) might be perceived negatively. The book was part of a supervisory training course that Sandra attended and is connected with her professional role. In contrast, Sandra's bracelet is an object she wears on a daily basis. It is made up of a series of links, retelling a story of her life, capturing memorable events that create, celebrate and promote self-expression. As she put it:

Is there anything I've given you that give you concern?[laughs] Like my bracelet [touches bracelet] and my book [touches book]. . . Thinking, oh my God I live by my book. But I think it's because it comes out with my bag and it's in my bag. It's visual and I'm a visual person . . . just the way you were questioning. So the book, it's in your bag and it comes out every day and then it goes back in (. . .) as if (. . .) as if [laughs] it's a bit of a (. . ) needy thing. Whether I really know what I'm doing . . .

(Figure5) 
As with words, images do not represent the only truth, and there is a need to resist this process as one that "assumes 'a/the truth' lurks behind those images", or that, as Sandra appears to assume (figure 5), the researcher is possibly trying to 'catch her out' and reveal the 'truth' about her (Reavey, 2011, p. 10). The ontological underpinning of qualitative research is the notion of multiple truths, which is supported by one of the tenants of IPA, where there is no single truth, but the experience of the individual (Smith et al., 2009).

Whilst many of the participants brought more than one image or object, Susie forgot to bring her object (a sponge) to the interview. Yet, the physical absence of Susie's object does not deter from the fact that it features significantly during the interview, emphasising the aforementioned need for the narrative to bring imagery to life. The necessity for words is further supported by Firth (2011), who, in her research, explored 19 women's experiences of cancer and chemotherapy. The women were given cameras to capture their thoughts and feelings associated with their medical treatment. Due to some practical (forgetting to take camera) or, at times, technical (flash did not work) issues; some of the women did not produce all or some of the intended photographs. Nevertheless, these 'missing' photographs "evoked discussions as vivid, engaging and detailed as those stirred up by those photographs which can be handled, stored, stroked and examined during the interview" (Firth, 2011, p. 59). This demonstrates not only the relevance of words to the generation of knowledge, but also the effort involved and the thought process associated with producing an image. For Susie; the receiving of the pre-interview participant information documentation provoked a clear image in her mind that represents her transitional experience - that of a natural sponge. As she puts it:

As soon as you said to me that I needed an object it came into my head. There wasn't any other question of what it would be . .

Despite forgetting to bring it to the interview, like the women in Firth's (2011) research, Susie was able to narrate her object through vivid description. Questions are asked relating to the sponge as if it were sitting there on the table between the participant and researcher, as Susie pointed to a void - bringing the image from a state of absence to presence. 


\section{Possibilities}

Despite the limitations associated with combining IPA and visual methods, there are also a number of advantages. The visual representation in this study is created by the participants. This is sometimes referred to as auto-driving, when the imagery is generated by the research participant (Heisley \& Levey, 1991) and serves to encourage agency and control of the knowledge generation (Silver, 2013). An array of material is selected by the participants to visually represent their experience of role transition. These include 'found' images, objects, personal artefacts and a drawing. Because these materials could be described as both abstract and familiar, they are open to multiple interpretations. Therefore, as previously suggested, it is important to ground the analysis in the participants' own narrative connected to their visual representations, this is often referred to as auteur theory (Mannay, 2016; Rose, 2012). This study supports the principles of auteur theory whilst simultaneously combining a visual method alongside IPA.

It is particularly evident within the circular two-stage interpretation process known as double hermeneutics, originally outlined by Smith et. al. (2009) which is an approach that involves the participant and researcher making sense of the experience being narrated. This is not undertaken concurrently and is the reason why this stage of the research process is time-consuming. The interpretation by the researcher may also on occasion, bring to light a meaning that the participant had not understood. The hermeneutic circle is the researcher getting near and far from the data. The study drawn upon in this paper, contributes to a new and emerging concept within IPA where the double hermeneutic has been extended to a triple hermeneutic endeavour. This relates to meaning making of an experience which relates to words and visuals. This is when the researcher is making "sense of the participants' interpretation of their visual representation of their experience" (Kirkham et al., 2015, p. 400).

Within this study, visual material appears to serve as a means to enable participants to show as well as tell their transitional story. The visual images and objects provided by the participants are used as a basis for the interview, 
enabling the participants' verbal accounts to be steered and expanded upon (Lachal, et al., 2012). Coupled with this is a commitment of IPA which includes the phenomenological requirement to understand participants. This study suggests that the use of visual material can evoke verbal data that connects the spoken narrative with the visual representation. It can be seen as providing an additional mode through which paricipants recount their stories and 'give voice' to their experience (Larkin et al., 2006; Reavey, 2011; Rose , 2012; Silver, 2013).

For example, Susie's (absent) sponge involves water. She describes the sponge as: An average one that you would buy, specifically like the ones from the sea. She also expresses this linguistically through the use of verbs and adjectives associated with water as she describes her transitional experience to include words such as drift, seep and dripping. Towards the end of her interview Susie becomes more literal with her metaphors as if reinforcing her lived experience:

I was kind of thrown in the deep end. You just have to sink or swim.

Similarly, another participant, Carol, uses images associated with adverse weather conditions to represent her experience. She became a manager at a time when the team was experiencing signficant instability. Carol uses her image of the main character of the film The Wizard of Oz, Dorothy, depicted in a tornado to illustrate her experience of confusion and change:

. . . getting sucked up into this whirlwind of chaos [laughs] or what felt like chaos when I first started. Hmmm and then when the dust kind of settled, I suppose and being in this completely different, very similar with lots and lots of familiarity but a very very different world at the same time.

(Figure6) 
By the end of her interview, Carol appears to 'become' this character, Dorothy, who infamously taps her feet together in a desire to return to familiar surroundings - home. Carol says:

Yeah, I'm tapping my feet . . . Yep, tapping my ruby slippers together . . you know I think she [Dorothy] had a fantastical journey along the way and that's what I'm choosing to embrace at the moment.

Within this study, conversations about feelings emerged early on in the participants' research interviews. These included feelings associated with loneliness, isolation, inadequacy, fear and confusion. This might partly be due to them being invited to represent how they felt about their transition visually. Talk of their image or object initiated the interview as they were asked how they had made their selection. The aim of such discussions was to promote a sense of agency, involvement and control of the research process on the part of the participant. This dialogue appears to have encouraged the participants to connect with their images and give rise to what Reavey $(2011$, p. 7) refers to as "emotionality". Similarly, Silver (2013, p. 157) argues that unlike words, images can evoke "deeper layers of human consciousness" meaning that the use of visual material seemed the initial rapport building within the research interview. Consequently, how they are feeling about their new role is both the focus of the research interview and their image-making. There is a growing emphasis on understanding how people experience their lives as well as how they talk about it (Smith, 2015). It is argued that the general use of visual data affords participants control and active agency in the research process (Reavey, 2011). The images generated by the participants included in this paper are personal objects (e.g. Sandra) and images that they found rather than authored themselves. Whilst the images are generated by the participant, without the accompanying narrative they can remain inconsequential. Therefore the participants' verbal account places them in the position of the instigator of knowledge that is generated by their lived experience.

\section{Conclusions}


The design of this study assumed that the images selected by the participants would provide a stimuli for elucidating discussion. Yet, they became much more than this. The images formed a central part of the interviews, even in their absence. Talk of the image(s) or object(s) shaped the focal point of the initial stages of the interview, however the visual representations also formed an integral part of the process used to recount experiences. When reflecting on their associated feelings with transition, the objects appear to become significant as participants interact and became tactile with them.

It is difficult to speculate whether the findings of the study would have been different had the participants all made (self-authored) their own images rather than selected visual material that they had found or already existed. What is clear is that the process of selecting visual images allowed the participants the time to reflect on the topic they were invited to explore which produced a rich array of visual material. A more immediate connection between the research and data developed as participants arrived ready to share a visual representation of their transition into management. This contributed to gaining a deeper understanding of the participants' experiences through the use of visual methods in combination with IPA. In contrast to Kirkham et al. (2015) research where participants are invited to draw an image during the interview, in this study, the selection of an image prior to the interview adds a new dimension to the emerging use of IPA together with visual methods. Prior selection offers participants' time to carefully consider their choice of visual representation. Used as a catalyst for the interview, talk of images and objects shape the start of the participants' stories.

Forming a connection to images and objects, both prior and during the interview, suggests that the visual material takes on a different form and becomes more than a representation. They are personal and meaningful; offering participants a means of manifesting the complex and internal process of transition (Bridges, 2003). They are also mediators, serving as "material gobetweens" (Prosser, 2011, p. 484) to help express difficult and elusive emotions (Kearney \& Hyle, 2004). Along with words, the visuals give shape and voice to ideas and experience (Chalfen \& Lutrell, 2010). 
This contributes to gaining a deep understanding of the participants' experiences through the use of visual methods in combination with IPA, encouraging stories that would not have been possible in the absence of images. Adding to the work of Kirkham et al. (2015), the IPA six-step approach is adapted, where sections of the transcript are examined alongside the accompanying visual image(s), which produces a clustering of thematic material. The approach utilised in this study contributes to the growing methodological innovations and developments in IPA. It also offers the potential to gain deeper and alternative perspectives into transition which previously remain unseen and their accompanying narrative unheard (Clark \& Morriss, 2017). Therefore, visual methods provide depth to interviews and richness to the data eliciting a broader understanding of transition. The flexibility of IPA provides a framework upon which to analyse, structure and present the visual and narrative data. 


\section{References}

Boden, Z., Larkin, M., \& Malvika , I. (2019). Picturing ourselves in the world: Drawings, interpretative phenomenological analysis and the relational mapping interview. Qualitative Research in Psychology, 16(2), 218-236. doi:10.1080/14780887.2018.154067

Bridges, W. (2003). Managing transitions (2nd ed.). New York: Perseus Books.

British Association of Social Work. (2012). The code of Ethics for Social Work - Statement of Principles. Birmingham: BASW. Retrieved July 6, 2015, from http://cdn.basw.co.uk/upload/basw_112315-7.pdf

Brocki, J. M., \& Wearden, A. J. (2006). A critical evaluation of the use of interpretative phenomenological analysis (IPA) in health psychology. Psychology and Health, 21(1), 87-108.

Burgess, H., \& Laurance, J. (2007). Reflections on creativity in social work and social work education. Southampton: Higher Education Academy.

Chalfen, R., \& Lutrell, W. (2010). Lifting up the voices of participatory research. Visual Studies, 25(3), 197-200.

Clark, A., \& Morriss, L. (2017). The Use of Visual Methodologies in Social Work Research over the last decade: A narrative review and some questions for the future. Qualitative Social Work, 16(1), 29-43.

Cronin-Davis, J., \& Mayers, C. A. (2009). Occupational therapy and interpretative phenomenological analysis: comparable research companions? British Journal of Occupational Therapy, 72(8), 332-228.

Del Busso, L. (2011). Using photographs to explore the embodiment of pleasure in everyday life. In P. Reavey (Ed.), Visual Methods in Psychology - Using and Interpreting Images in Qualitative Research (pp. 43-54). East Sussex: Routledge.

Emmison, M., Smith, P., \& Mayall, M. (2012). Researching the Visual (2nd ed.). London: Sage.

Firth, H. (2011). Narrating biographical disruption and repair: exploring the place of absent images in women's experiences of cancer and chemotherapy. In P. Reavey (Ed.), Visual Methods in Psychology - Using and Interpreting Images in Qualitative Research (pp. 43-54). East Sussex: Routledge.

Guillemin, M. (2004). Understanding illness: Using drawings as a research method. Qualitative Health Research, 14, 272-289.

Hefferon, K., \& Gil-Rodriguez, E. (2011). Interpretative phenomenological analysis. Methods, 24(10), 756-759.

Heisley, D. D., \& Levey, S. J. (1991). Autodriving: A Photoelicitation Technique. Journal of Consumer Research, 18, 257-272.

Houston, S., \& Mullen-Jensen, C. (2012). Towards depth and width in qualitative social work: Aligning IPA with the theory of social domains. Qualitative Social Work, 0(00), 1-16.

Huss, E. (2012). What We See and What We Say: Combining Visual and Verbal Information within Social Work Research. The British Journal of Social Work, 42(8), 1440-1459. 
International Federation of Social Work . (2014). Global Definition of Social Work. Retrieved April 24, 2016, from http://ifsw.org/policies/definition-of-social-work/

Kearney, K. S., \& Hyle, A. E. (2004). Drawing out emotions: the use of participant-produced drawings in qualitative inquiry. Qualitative Research, 4(3), 361-382.

Kirkham, J. A., Smith, J. A., \& Havsteen-Franklin, D. (2015). Painting pain: An interpretative phenomenological analysis of representations of living with chronic pain. Health Psychology, 34(4), 398-406.

Kirkham, J. A., Smith, J. A., \& Havsteen-Franklin, D. (2015). Painting Pain: An Interpretative Phenomenological Analysis of Representations of Living with Chronic Pain. Health Psychology, 34(4), 398-406.

Lachal, J., Speranza, M., Taïeb, O., Falissard, B., Lefèvre, H., Moro, M., \& Revah-Levy, A. (2012). Qualitative research using photo-elicitation to explore the role of food in family relationships among obese adolescents. Appetite, 58(3), 1099-11.

Larkin, M., Watts, S., \& Clifton, E. (2006). Giving voice and making sense in interpretative phenomenological analysis. Qualitative Research in Psychology, 3(2), 102-120.

Lee, J., \& Skewes McFerran, K. (2015). Applying Interpretative Phenomenological Analysis to Video Data in Music Therapy. Qualitative Research in Psychology, 12(4), 367-381.

Loo, E. W. (2012). Every contact leaves a trace: IPA as a method for Social Work research. Retrieved May 22, 2015, from http://www.auamii.com/proceedings_Phuket_2012/Loo.pdf

Mannay, D. (2013). 'Who put that on there. . . why why why?' Power games and participatory techniques of visual data production, ,. Visual Studies, 28(2), 136-146.

Mannay, D. (2016). Visual, Narrative and Creative Research Methods- Application, reflection and ethics. Oxon: Routledge.

Mazzei, L. A., \& Jackson, A. Y. (2012). Thinking with Theory in Qualitative Research: Viewing data across multiple perspectives. London: Routledge.

Palaloukas, P., Quincey, K., \& Williamson, I. R. (2017). Venturing into the Visual Voice: Combining photos and interviews in phenomenological inquiry around marginalisation and chronic illness. Qualitative Research in Psychology, 14(4), 415-441.

Pauwels, L. (2015). Participatory visual research revisited: a critical constructive assessment of epistemological, methodological and social activist tenents. Ethnography, 16(1), 95-117.

Pietkiewicz, I., \& Smith, J. A. (2014). A practical guide to using Interpretative Phenomenological Analysis in qualitative research psychology. Psychological Journal, 20(1), 7-14.

Pringle, J., Drummond, J., McLafferty, E., \& Hendry, C. (2011). Interpretative phenomenological analysis: a discussion and critique. Nurse Researcher, 18(3), 20-24.

Prosser, J. (2011). Visual methodology - Towards a more seeing research. In N. K. Denzin, \& Y. S. Lincon (Eds.), The Sage Handbook of Qualitative Research (4th ed., pp. 479-496). London: Sage. 
Ray, J. L., \& Smith, A. D. (2012). Using photographs to reserach organizations: Evidence, considerations and application in a field study. Organizational Research Methods, 15, 288315.

Reavey, P. (2011). Visual Methods in Psychology - Using and Interpreting Images in Qualitative Research. East Sussex: Routledge.

Reavey, P. (2011). Visual Methods in Psychology - Using and Interpreting Images in Qualitative Research. East Sussex:: Routledge.

Rose , G. (2012). Visual Methodologies -An Introduction to Researching with Visual Materials (3rd ed.). London: Sage.

Shinebourne, P., \& Smith, J. A. (2011). Images of addition and recovery: An interpretative phenomenological analysis of the experience of addiction and recovery as expressed in visual images. Drugs: education, prevention and policy. 18(5), 313-322.

Silver, J. (2013). Visual methods. In C. Willig (Ed.), Introducing Qualitative Research in Psychology (pp. 156-165). Berkshire: Open University Press/McGraw-Hill Education.

Smith, J. A. (2015). Qualitative Psychology - A practical guide to research methods (3rd ed.). (J. A. Smith, Ed.) London: Sage.

Smith, J. A., Flowers, P., \& Larkin, M. (2009). Interpretative Phenomenological Analysis - Theory, Method and Research. London: Sage.

Thomson, P. (2009). Doing visual research with children and young people. (P. Thomson, Ed.) Oxon: Routledge.

Trevithick, P. (2005). Social Work Skills - a practice handbook (2nd ed.). Berkshire: Open University Press.

Warren, J. (2007). Service user and carer participation in social work. London: Sage. 